\title{
Worry and problem-solving skills and beliefs in primary school children
}

\section{Article}

Accepted Version

Parkinson, M. and Creswell, C. (2011) Worry and problemsolving skills and beliefs in primary school children. British Journal of Clinical Psychology, 50 (1). pp. 106-112. ISSN 2044-8260 doi: https://doi.org/10.1348/014466510X523887 Available at https://centaur.reading.ac.uk/17282/

It is advisable to refer to the publisher's version if you intend to cite from the work. See Guidance on citing.

To link to this article DOI: http://dx.doi.org/10.1348/014466510X523887

Publisher: Wiley

All outputs in CentAUR are protected by Intellectual Property Rights law, including copyright law. Copyright and IPR is retained by the creators or other copyright holders. Terms and conditions for use of this material are defined in the End User Agreement.

\section{www.reading.ac.uk/centaur}

\section{CentAUR}

Central Archive at the University of Reading

Reading's research outputs online 
British Journal of Clinical Psychology- IN PRESS 2010

\title{
Brief report
}

Worry and problem-solving skills and beliefs in primary school children

Monika Parkinson \& Cathy Creswell

\author{
Berkshire Child Anxiety Clinic \\ University of Reading
}

Contact information:

Dr Monika Parkinson

Berkshire Child Anxiety Clinic

School of Psychology and Clinical Language Sciences

University of Reading

Whiteknights

Reading

Berkshire RG6 6AL

Tel: 01183786667

Fax: 01183786665

Email: m.b.parkinson@reading.ac.uk 


\section{Abstract}

Objective: To examine the association between worry and problem-solving skills and beliefs (confidence and perceived control) in primary school children.

Method: Children (8-11 years) were screened using the Penn State Worry Questionnaire for Children (PSWQ-C). High $(n=27)$ and low $(n=30)$ scorers completed measures of anxiety, problem-solving skills (generating alternative solutions to problems, planfulness and effectiveness of solutions) and problem-solving beliefs (confidence and perceived control). Results: High and low worry groups differed significantly on measures of anxiety and problem-solving beliefs (confidence and control) but not on problem-solving skills. Conclusions: Consistent with findings with adults, worry in children was associated with cognitive distortions, not skills deficits. Interventions for worried children may benefit from a focus on increasing positive problem-solving beliefs.

Words $=114$ 


\section{Introduction}

Although worry represents a universal human experience, it is more frequent and less controllable in those experiencing anxiety disorders (Craske, Rapee, Jackel, \& Barlow, 1989), and is hypothesised to maintain high levels of anxiety and prevent effective problem-solving.

Specifically, Borkovec suggests that worry may serve as a form of cognitive avoidance, in which people have repetitive thoughts about problems, without actually engaging in any helpful problem-solving behaviours (Borkovec, 1985). Problem-solving also has an important role in Dugas' theory of intolerance of uncertainty, which is characterised by negative beliefs about problems and one's ability to problem-solve (and further characterised by aversion to uncertainty, positive beliefs about worry and cognitive avoidance), and leads directly to increased levels of worry (e.g., Dugas, Gagnon, Ladouceur, \& Freeston, 2000; Dugas, Letarte, Rheaume, Freeston, \& Ladouceur, 1995; Ladouceur, Blais, Freeston \& Dugas, 1998 ). Consistent with this theory, studies with adult populations (within both clinical and nonclinical populations) have demonstrated that those who score highly on measures of worry do not show impairments in problem-solving skills in comparison to those with low scores, however, differences are apparent in relation to their cognitions about problem-solving (e.g., Davey, 1994). Specifically, compared to those with low levels of worry, participants with high levels of worry report lower problem-solving ability, confidence and perceived control (Davey, 1994; Dugas et al., 1995; Ladouceur et al., 1998). Furthermore, Davey, Jubb, and Cameron (1996) experimentally manipulated participants' problem-solving confidence and found that reduced confidence led to a subsequent increase in catastrophic worry. 
Few studies have addressed the association between problem-solving skills and/or beliefs and worry specifically in younger populations. An exception is the study of Laugesen, Dugas, and Bukowski (2003) which found a relationship between negative problem-solving orientation (beliefs and emotions about problems and own ability to cope) and higher worry in an adolescent sample. Also of relevance, Reinecke, DuBois, and Schultz (2001) found an association between higher anxiety and increased negative problem-solving orientation and reduced rational problem-solving (increased avoidance and impulsivity) in adolescents (aged 12-18 years). With a younger group, Szabo and Lovibond (2004) found clinically anxious children (aged 8-13 years) reported fewer problem-solving thoughts and successful problemsolving behaviours than a nonclinical comparison group. These studies are, however, limited by self-report assessments of problem-solving 'skills' so it is unclear whether problemsolving skills or beliefs were assessed.

Where problem-solving has been considered within treatment programmes for youth, the focus has tended to be on problem-solving skills, rather than beliefs and, despite the lack of support for problem solving skills deficits in adults, it is plausible that poor problem-solving skills may precede the development of poor problem-solving confidence in high worriers. Problem-solving interventions have been used with some success to improve problemsolving skills, reduce aggressive behaviour, and promote social competence (Coleman, Wheeler, \& Webber, 1993; Pelligrini \& Urbain, 1985; Urbain \& Kendall, 1980) however, the impact of problem-solving skills training on worry has not been formally evaluated.

The aim of the present study was to compare problem-solving, in terms of both skills and beliefs, in children who experience high and low levels of worry, and to establish whether associations are specific to worry, as opposed to the general construct of anxiety. 


\section{Method}

Participants

Children were recruited through primary schools in Berkshire, U.K. Children, aged 8-11 years, from eight primary schools were invited to participate $(n=806)$. Where children and a parent/guardian provided consent $(n=247,30.6 \%)$ children were visited at school and administered $(n=240)$ the Penn State Worry Questionnaire for Children (PSWQ-C; Chorpita, Tracey, Brown, Collica, \& Barlow, 1997). The scores showed a bimodal distribution and groups were formed according to scores falling immediately above and below each mode (which represented the upper and lower 12.5 centiles). Children who scored in the top $12.5 \%(n=30)$ were assigned to the 'high worry' group (PSWQ-C mean $=33.67, \mathrm{sd}=23.29$, range $=27-42)$; children who scored in the bottom $12.5 \%(n=30)$ were assigned to the "low worry' group (PSWQ $-\mathrm{C}$ mean $=8.17, \mathrm{sd}=2.17$, range=2-11). To ensure the high worry group was showing a consistent trait, children were reassessed on the worry questionnaire, on average, 10 weeks later. Three participants in the 'high worry' group showed marked reductions on the PSWQ-C at the second assessment (mean PSWQ $=12.66$ ) so were withdrawn $(n=27)$. The low and high worry groups didn't differ in terms of distribution of age (low worry: mean = 116 months, high worry: mean = 114 months), family composition (low worry: $80 \%$ parents married/cohabitating; high worry: $72 \%$ parents married/cohabitating) or ethnicity (low worry: $77 \%$ White British; high worry $74 \%$ white British); furthermore the ethnicity of the sample did not differ from U.K. national schools statistics (e.g., 77\% vs 78\% White British). There were, however, more boys in the low than high worry group (low worry: 63\% male; high worry $33 \%$ male, $\chi^{2}(1)=5.18, p=0.02$ ).

\section{Measures}

Penn State Worry Questionnaire for Children (PSWQ-C; Chorpita et al., 1997) 
The PSWQ-C was used as a child self-report measure of the extent and controllability of worry. The PSWQ-C consists of 14-items to which the child responds on a 4-item Likert scale ranging from 0 (not at all true) to 3 (always true). The PSWQ-C is widely used and has demonstrated good test-retest reliability, internal consistency, convergent and discriminant validity (Chorpita et al., 1997). For the current study, internal consistency for this measure was high $(\alpha=0.94)$.

Revised Children's Manifest Anxiety Scale (RCMAS; Reynolds \& Richmond, 1978)

The RCMAS is a 37-item self-report questionnaire that assesses trait anxiety in children. The RCMAS comprises 28 anxiety items and a 9 item lie scale, to which the child indicates agreement or disagreement. The RCMAS is a widely used instrument and has been shown to be reliable and valid for children aged 6-19 years (Reynolds \& Paget, 1983). The measure has good internal consistency (Reynolds \& Richmond, 1978), content, construct and covergent validity (Reynolds, 1985).

Alternative Solutions Test (AST; Caplan, Weissberg, Bersoff, Ezekowitz, \& Well, 1986) The AST provides a measure of children's ability to generate solutions to age-relevant hypothetical problems, as well as the effectiveness and level of planfulness of those solutions. Children are given home and school based scenarios that include a problem and are asked to generate different solutions to overcome the problem and to continue until they are no longer able to think of ideas any new solutions. The number of alternative solutions is recorded, and the type of solution, its effectiveness and planfulness are coded. The AST has been found to have high test-retest reliability (Caplan et al., 1986). Thirteen (23\%) responses were coded by two raters blind to condition, high levels of inter-rater reliability were found (response category: kappa $=0.91, p<.001$; response effectiveness: kappa $=0.96, p<.001 ;$ response planfulness: kappa $=0.85, p<.001)$. 
Problem-Solving Inventory - adapted for children (PSI-C)

The Problem-Solving Inventory (PSI; Heppner \& Peterson, 1982) was adapted for the current study to assess children's perceived problem-solving ability and style. The PSI is a 35-item questionnaire designed to measure problem-solving confidence, approach-avoidance style and personal control (of emotions and behaviours whilst problem-solving). For the purposes of the present study the number of items was reduced to 12 (four items in each subscale), only incorporating those items which would be meaningful to the younger population. The wording of the remaining items was also adapted in consultation with four 7-10 year old children. ${ }^{1}$

Children were asked to indicate the extent to which each item was true of them on a scale from 1 (almost never true) to 4 (almost always true). Five items were reversed to reduce response bias. Lower scores indicate a more positive view of problem-solving (i.e. greater confidence and control and less avoidance). The subscales achieved satisfactory internal consistency ( $\alpha=0.84$ (personal control); 0.76 (confidence)), with the exception of approachavoidance for which the internal consistency was low $(\alpha=0.17)$. The approach-avoidance scale was therefore not included in analyses.

\section{Procedure}

Following the initial screening phase, children in both the high and low worry groups individually completed an assessment of worry, anxiety and problem-solving (skills and cognitions).

\footnotetext{
${ }^{1}$ Revised inventory available from the first author
} 


\section{Results}

Distributions of the data were checked to confirm that the assumptions of parametric tests were met. Where assumptions were not met, removal of one outlier (anxiety scores for low worry group) and logarithmic transformation (AST scores for low worry group) improved the distribution to meet the necessary assumptions.

High vs. Low worriers

An independent measures MANOVA was used to examine the effect of group membership on the dependent variables (number of alternative solutions, problem-solving effectiveness, planfulness, problem-solving confidence and control). Gender was entered as a covariate. There was a significant effect of group, which remained significant after covarying for gender $(F(5,50)=10.16, p<.001)$. Between-subjects effects were highly significant for problem-solving beliefs (problem-solving confidence $(F(1,54)=37.72, p<.001)$ and perceived control $(F(1,54)=37.26, p<.001)$, but not for problem-solving skills (number of solutions generated, effectiveness and planfulness), see table 1.

Table 1 approximately here

As expected, the high and low worry groups showed a highly significant difference on the anxiety measure (see table 1), therefore linear regressions were carried out to examine further the relationship between worry and the problem-solving variables, after controlling for anxiety. Worry was found to make a significant unique contribution to 
explaining problem-solving confidence $(B=0.14, \operatorname{SE}(B)=0.05, \beta=0.43, p<0.01)$, but not problem-solving control $(B=0.10, \operatorname{SE}(B)=0.06, \beta=0.26, p=0.08)$.

\section{Discussion}

The findings of the current study suggest high worry in children is associated with negative beliefs about problem-solving, specifically poor problem-solving confidence and low perceived problem-solving control, yet are not associated with problem-solving skills deficits in generating solutions, and the planfulness and effectiveness of solutions. Furthermore, when controlling for the effects of anxiety, the results suggest a specific association between problem-solving confidence and worry. These findings are consistent with Dugas' proposal that negative belief's about problems and one's ability to solve these maintains high levels of worry, and previous studies that demonstrated worry and anxiety were associated with a more negative problem-solving orientation for non-clinical (Laugesen, Dugas \& Bukowski, 2003) and clinical adolescent populations (Reinecke, Du Bois \& Schultz, 2001). Unlike Szabo and Lovibond (2004), however, skills deficits were not found (although notably that study relied on self-reported skills deficits, which may arguably be more an assessment of problem solving cognitions). Our findings are consistent with studies with adults that have suggested negative problem-solving beliefs (and not skills deficits) are associated with increased worry (Davey, Jubb \& Cameron, 1996), and further examination of the nature of the relationship between problem-solving beliefs and worry in youth is clearly warranted.

The current study used a novel measure of problem-solving beliefs, adapted for children from the Problem-Solving Inventory (PSI; Heppner \& Peterson, 1982). The measure had good face validity and psychometric properties of the confidence and control scales, however, the internal consistency of the avoidance scale was inadequate. Thus the current study was 
limited to exploration of problem-solving 'skills' and 'beliefs' and was unable to assess problem-solving 'style', which may well distinguish children with high and low worry (e.g., Barrett, Dadds, \& Rapee, 1996; Reinecke et al., 2001). Limitations regarding generalisability should be acknowledged. The study response rate was relatively low which may have introduced a bias, although it is encouraging the final sample did not differ from UK national statistics on demographic factors. In forming the two worry groups from our community sample by using high and low cut-off scores on the worry measure, there is the possibility that the low worry scores do not represent a normative group and replication comparing, for example, children with Generalised Anxiety Disorder to non-clinical controls is warranted. Whether the data can be generalised to clinical populations also requires further study, however, it is notable that the level of anxiety reported by the 'high worry' group approached clinical cut-offs (Stallard, Velleman, Langsfor, \& Baldwin, 2001).

The current study provides support for an association between worry and negative problemsolving beliefs, specifically low problem-solving confidence, in primary school aged children, and their application to clinical populations, warrants further research attention. Early investigations with young adults have shown promising outcomes from cognitive approaches aimed at negative problem orientation (Leger, Ladouceur, Dugas, \& Freeston, 2003). Our findings, while preliminary, are consistent with the suggestion that interventions with children who experience high levels of worry may benefit from the inclusion of procedures to specifically target problem-solving beliefs. 
Table 1

Worry, anxiety, problem-solving beliefs and skills

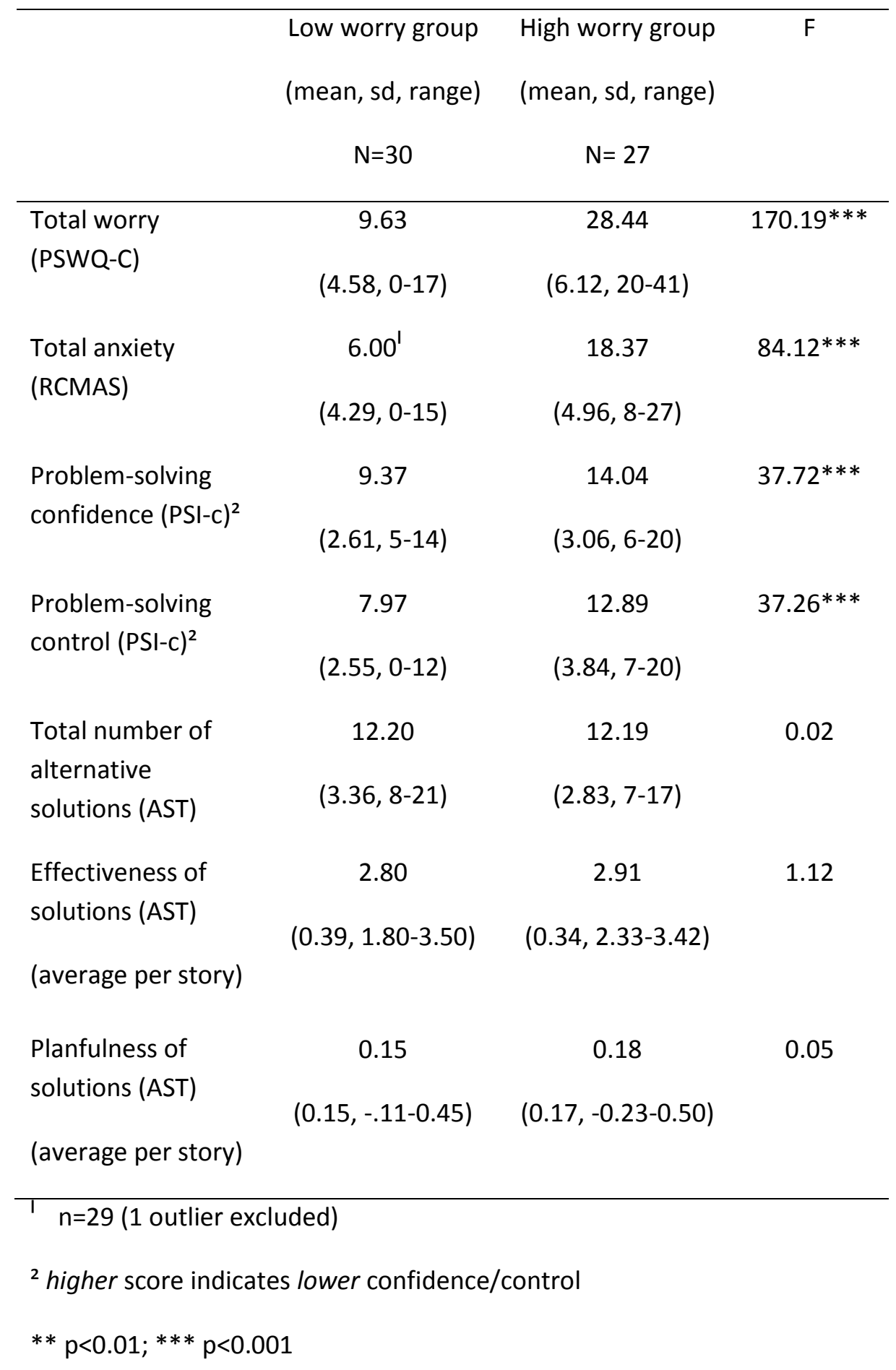




\section{References}

Barrett, P.M., Dadd, M.R., Rapee, R.M. (1996). Family treatment of childhood anxiety: A controlled trial. Journal of Consulting and Clinical Psychology, 64, 333-342.

Borkovec, T.D. (1985). Worry: A potentially valuable concept. Behaviour Research and Therapy, 23, 481-482.

Caplan, M., Weissberg, R.P., Bersoff, D., Ezekowitz, W., \& Well, M.L. (1986). The Middle School Alternative Solutions Test (AST) Scoring Manual. Unpublished manuscript.

Chorpita, B.F., Tracey, S.A., Brown, T.A., Collica, T.J., \& Barlow, D.H. (1997). Assessment of worry in children and adolescents: An adaptation of the Penn State Worry questionnaire. Behaviour Research and Therapy, 35, 569-581.

Coleman, M., Wheeler, L., \& Webber, J. (1993). Research on interpersonal problem-solving training: A review. Remedial and Special Education, 14, 25-37.

Craske, M., Rapee, R., Jackel, L., \& Barlow, D. (1989). Qualitative dimensions of worry in DSM-III-R generalised anxiety disorder subjects and nonanxious controls. Behaviour Research and Therapy, 27, 397-402.

Davey, G.C.L. (1994). Worrying, social problem-solving abilities, and social problem-solving confidence. Behaviour Research and Therapy, 32, 327-330.

Davey, G.C.L., Jubb, M., \& Cameron, C. (1996). Catastrophic worrying as a function of changes in problem-solving confidence. Cognitive Therapy and Research, 20, 333-344. Dugas, M.J., Gagnon, F., Ladouceur, R., \& Freeston, M.H. (1998). Generalised anxiety disorder: A preliminary test of a conceptual model. Behaviour Research and Therapy, 36, 215-226.

Dugas, M.J., Letarte, H., Rheaume, J, Freeston, M.H., \& Ladouceur, R. (1995). Worry and problem-solving: Evidence of a specific relationship. Cognitive Therapy and Research, 19, 109-120. 
Heppner, P.P., \& Petersen, C.H. (1982). The development and implications of a personal problem-solving inventory. Journal of Counselling Psychology, 29, 66-75. Ladouceur, R., Blais, F., Freeston, M.H., \& Dugas, M.J. (1998). Problem-solving and problem orientation in generalized anxiety disorder. Journal of Anxiety Disorders, 12, 139-152. Laugesen, N., Dugas, M.J., \& Bukowski, W.M. (2003). Understanding adolescent worry: The application of a cognitive model. Journal of Abnormal Child Psychology, 31, 55-64. Leger, E., Ladouceur, R., Dugas, M.J., Freeston, M.H. (2003). Cognitive-behavioural treatment of generalised anxiety disorder among adolescents: A case series. Journal of the American Academy of Child and Adolescent Psychiatry, 42, 327-330.

Pellegrini, D.S., \& Urbain, E.S. (1985). An evaluation of interpersonal cognitive problem solving training with children. Journal of Child Psychology and Psychiatry, 26, 17-41. Reinecke, M.A., DuBois, D.L., \& Schultz, T.M. (2001). Social problem-solving, mood, and suicidality among inpatient adolescents. Cognitive Therapy and Research, 25, 743-756. Reynolds, C.R. (1985). Multitrait validation of the Revised Children's Manifest Anxiety Scale for children of high intelligence. Psychological Reports, 56, 402.

Reynolds, C.R., \& Paget, K.D. (1983). National normative and reliability data for the Revised Children's Manifest Anxiety Scale. School Psychology Review, 12, 324-336.

Reynolds, C.R., \& Richmond, B.O. (1978). What I think and feel: A revised version of the Children's Manifest Anxiety Scale. Journal of Abnormal Child Psychology, 5, 237-249. Stallard, P., Velleman, R., Langsfor, J., \& Baldwin, S. (2001). Coping and psychological distress in children involved in road traffic accidents. British Journal of Clinical Psychology, 40, 197208.

Szabo, M., \& Lovibond, P.F. (2004). The cognitive content of thought-listed worry episodes in clinic-referred anxious and nonreferred children. Journal of Clinical Child and Adolescent Psychology, 33, 613-622. 
Urbain, E.S., \& Kendall, P.C. (1980). Review of social-cognitive problem-solving interventions with children. Psychological Bulletin, 88, 109-143. 